\title{
Kulturell og musikalsk aktivitet blant norske leger
}

\begin{abstract}
BAKGRUNN Norske legers kulturelle og musikalske aktivitet ble kartlagt i 1993. Vi ønsket å undersøke deres kulturelle og musikalske aktivitet på nytt, analysere utviklingen og studere sammenhengen med tilfredshet, helsetilstand og andre fritidsaktiviteter.

MATERIALE OG METODE En spørreskjemaundersøkelse ble høsten 2010 utført blant et representativt utvalg yrkesaktive norske leger. Samme spørsmål som i 1993 ble stilt, og svarene ble også sammenholdt med Statistisk sentralbyrås befolkningsstudier. En egenutviklet kulturindeks ble beregnet.
\end{abstract}

RESULTATER I alt 1019 leger (70\%) besvarte spørsmålene. De rapporterte høyere kulturell aktivitet i 2010 enn i 1993, målt som lesing av ikke-medisinsk litteratur og besøk på kino, teater og konserter. Særlig høy var den musikalske egenaktiviteten, der $58 \%$ anga at de kunne spille et instrument og $21 \%$ at de spilte regelmessig, noe som er høyere enn hos andre akademikere. Vi fant en signifikant sammenheng mellom legenes kulturbruk og deres jobbtilfredshet, generelle tilfredshet, selvvurderte helsetilstand og fysiske aktivitet. De mest kulturelt aktive legene er også mest tilfreds med både jobben og livet for øvrig. De har dessuten best selvvurdert helse.

FORTOLKNING Norske leger prioriterer kulturelle og musikalske aktiviteter. At leger har et særlig nært forhold til musikk, er mer enn en myte.

«Every day do some reading or work apart from your profession.» Disse ordene fra sir William Osler (1849-1919) har vært til inspirasjon for mange generasjoner leger (1). Dels handler det om avkobling fra krevende arbeidsoppgaver (både $\mathrm{i}$ omfang og karakter) som lege, dels om aktiviteter som kan være stimulerende og utviklende også for den medisinske virksomheten. Humanistiske fag kan gi bedre forståelse for de sammenhenger pasienter og leger lever og fungerer $\mathrm{i}$ og utvidede perspektiver på både pasientbehandling og organisering av helsevesenet (2). I tillegg diskuteres det om kulturell aktivitet i seg selv kan være helsebringende. Flere undersøkelser viser at det er sammenheng mellom kulturdeltakelse, kulturopplevelse og helse, men kvaliteten på studiene er variabel, og noen kausal forbindelse kan ikke dokumenteres (3-7).

Den medisinske tilknytning til kunst og kultur strekker seg tilbake til den greske mytologien. Legekunstens gud Asklepios (Æskulap) var sønn av Apollon, guden for musikk, poesi og alle kunstarter. En særlig nær forbindelse har det vært mellom medisin og musikk. En undersøkelse fra 1993 viste at norske leger var mer interessert $\mathrm{i}$ og opptatt av musikk enn akademikere flest (8).

I 1993 undersøkte vi også norske legers øvrige kulturelle aktiviteter (9). Vi fant en generelt høy grad av kulturell aktivitet til tross for stor arbeidsbelastning. I de nesten to tiårene som er gått siden denne undersøkelsen, er mye endret både i norsk medisin og i kulturlivet. Antallet leger har økt, lege- gruppen er blitt mer heterogen og kulturtilbudet er økt. Legenes arbeidstid har imidlertid endret seg lite fra 1994 og frem til i dag $(10,11)$. Samtidig har konkurransen om folks tid og oppmerksomhet blitt større. Dette gjelder også for legene.

Hvordan har legenes kulturelle og musikalske aktivitet endret seg? For å undersøke dette har vi gjennomført en ny spørreundersøkelse og på nytt sammenliknet med tilsvarende aktivitet i den norske befolkning og analysert utviklingen fra 1993.

\section{Materiale og metode}

Legeforeningens forskningsinstitutt har fra tidlig i 1990-årene gjennomført regelmessige spørreskjemaundersøkelser blant et representativt utvalg norske leger, det såkalte referansepanelet. Gjennom årene har det skjedd flere utskiftninger i panelet, bl.a. fordi mange er blitt pensjonister. Det er blitt fornyet og utvidet to ganger, sist i 2008, da det ble utvidet med en tilfeldig gruppe yngre leger som hadde fått autorisasjon etter år 2000.

Ved undersøkelsen i 2010 var kulturbruk og fritidsaktiviteter ett av seks temaer. Mange av spørsmålene fra 1993 ble gjentatt for å kunne sammenlikne svarene. En forskjell på spørreskjemaene var at det i 1993 ble spurt om hva slags bok man hadde lest siste døgn, mens det i 2010 ble spurt om hva slags bok man sist hadde lest. Dette ga færre svar på dette spørsmålet i 1993 enn i 2010 (tab 1).

Skjemaene ble utsendt høsten 2010, og det ble gjort én purring. Ingen av legene som svarte i 1993, var med i denne undersøkelsen.

\section{Magne Nylenna}

magne.nylenna@kunnskapssenteret.no Nasjonalt kunnskapssenter for helsetjenesten og

Institutt for helse og samfunn Universitetet i Oslo

og

Institutt for samfunnsmedisin

Norges teknisk-naturvitenskapelige universitet

Olaf Gjerløw Aasland

LEFO - Legeforskningsinstituttet

og

Avdeling for helseledelse og helseøkonomi

Institutt for helse og samfunn

Universitetet i Oslo

Engelsk oversettelse på www.tidsskriftet.no

HOVEDBUDSKAP

Norske leger har en høy kulturell aktivitet på fritiden, og aktiviteten er økt fra 1993 til 2010

Særlig høy er legenes musikalske aktivitet

Høy kulturell aktivitet samvarierer med høy jobbtilfredshet, god selvvurdert helse og fysisk aktivitet 
Tabell 1 Lesemønster for ikke-medisinsk litteratur basert på spørsmålet: «Hva slags bok leste du i løpet av siste døgn/sist (hvis flere, hvilken leste du mest i)?» Prosentandeler med $95 \%$ konfidensintervall. Signifikante forskjeller er uthevet.

\begin{tabular}{|c|c|c|c|c|}
\hline \multirow[b]{2}{*}{ Roman, novellesamling } & \multicolumn{2}{|c|}{$\begin{array}{l}\text { Alle svarere i } 1993 \\
\qquad(N=475)\end{array}$} & \multicolumn{2}{|c|}{$\begin{array}{l}\text { Alle svarere i } 2010 \\
(\mathrm{~N}=1004)\end{array}$} \\
\hline & 48,2 & $(43,7-52,7)$ & 69,9 & $(67,1-72,7)$ \\
\hline Skuespill, diktsamling & 2,1 & $(0,8-3,4)$ & 0,8 & $(0,3-1,4)$ \\
\hline Biografi, memoarer & 8,2 & $(5,7-10,7)$ & 5,6 & $(4,2-7,0)$ \\
\hline Naturvitenskap, teknikk, filosofi & 9,5 & $(6,9-12,1)$ & 7,0 & $(5,4-8,6)$ \\
\hline Samfunnsspørsmål, politikk, kunst, historie & 16,1 & $(12,8-19,4)$ & 10,1 & $(8,2-12,0)$ \\
\hline Religiøs litteratur & 6,5 & $(4,3-8,7)$ & 1,8 & $(1,0-2,6)$ \\
\hline Annet & 8,8 & $(6,3-11,4)$ & 4,9 & $(3,6-6,2)$ \\
\hline
\end{tabular}

Legenes oppgitte spesialitet er samlet $\mathrm{i}$ hovedgrupper som allmennmedisin, laboratoriemedisin, indremedisinske fag, kirurgiske fag, psykiatri og samfunnsmedisin. For å sammenlikne legenes kulturelle og musikalske aktivitet med aktiviteten i befolkningen for øvrig er respondenter med lang universitets- og høyskoleutdanning fra Statistisk sentralbyrås kulturbarometer 2008 og mediebarometer 2009 benyttet $(12,13)$.

For å undersøke i hvilken grad kulturbruk henger sammen med tilfredshet, helse og andre fritidsaktiviteter benyttet vi følgende mål: jobbtilfredshet, målt med ett samlemål basert på ti validerte spørsmål (14), subjektiv velvcere, målt med ett enkelt spørsmål: «Når du tenker på hvordan du har det for tiden, er du stort sett fornøyd, eller er du stort sett misfornøyd?», skåret på en skala fra 1 (svært misfornøyd) til 7 (svært fornøyd), egenvurdert helse, målt med ett spørsmål «Stort sett, vil du si at din helse er: dårlig (1 poeng), ikke helt god ( 2 poeng), god ( 3 poeng), svært god (4 poeng)», jobbstress, målt med Siegrists effort-reward- instrument, basert på ni validerte spørsmål (15), og trening og fysisk aktivitet, målt med spørsmålet: «Hvor ofte i løpet av siste år har du drevet med fysisk aktivitet for å trene eller mosjonere, f.eks. jogging, gått lengre turer, skiturer, drevet gymnastikk, svømt, spilt fotball, tennis o.1.?», med svaralternativene null ganger (1 poeng), én gang i måneden eller sjeldnere ( 2 poeng), 2-3 ganger i måneden (3 poeng), $1-4$ ganger i uken ( 4 poeng), hver dag eller nesten hver dag ( 5 poeng).

Som i 1993 har vi benyttet en indeks for legenes kulturelle aktivitet. Denne bygger på egenrapportert lesing av ikke-medisinsk litteratur i mer enn 20 minutter siste dag, det å spille et musikkinstrument og det å spille $\mathrm{i}$ orkester eller synge i kor (1 poeng for hver av de tre aktivitetene). Tilsvarende er det gitt poeng for besøk på kino, teater, opera, klas- siske konserter og konserter med populærmusikk ( 1 poeng for $1-4$ besøk og 2 poeng for fem eller flere besøk de siste 12 månedene). Den høyeste mulige skåren på indeksen er 13.

Vurdering av eventuelle statistisk signifikante forskjeller i sammenlikninger mellom grupper er basert på $95 \%$ konfidensintervall (KI). Bivariate korrelasjoner angis med Spearmans $\rho$ (rho), fordi mange av variablene som sammenliknes ikke er normalfordelte.

\section{Resultater}

Spørreskjemaet ble sendt ut til 1448 leger, og vi fikk svar fra 1019 (70\%). 37\% av svarerne var kvinner og $63 \%$ var menn. Gjennomsnittsalderen for de kvinnelige svarerne var 45,8 år (95\% KI: 44,9-46,7 år), for mennene var den 52,9 år (95\% KI $52,1-53,7$ år)

\section{Lesing}

$90 \%$ (95\% KI: 89-92\%) av legene hadde siste døgn lest en papiravis, $21 \%$ (95\% KI: 19-24\%) hadde lest ukeblader eller andre ikke-medisinske tidsskrifter og 50\% (95\% KI: $47-53 \%$ ) hadde lest ikke-medisinske bøker. Tilsvarende andeler blant akademikere $\mathrm{i}$ den norske befolkningen var henholdsvis $84 \%$ (95\% KI: $79-89 \%), 11 \%$ (95\% KI: 7-15\%) og $43 \%(95 \% \mathrm{KI}:$ $37-49 \%$ ) (12). Vurdert etter $95 \%$ konfidensintervall ligger legene så vidt over akademikere for øvrig i lesing av papiravis og klart over i lesing av ikke-medisinske tidsskrifter.

Det var $79 \%$ (95\% KI: $74-83 \%)$ av kvinnene som anga romaner og noveller som den ikke-medisinske boksjangeren de sist hadde lest, mot $65 \%(95 \% \mathrm{KI}$ : 61-69\%) av mennene. Tilsvarende var det $4 \%$ (95\% KI: 2-6\%) av kvinnene som anga litteratur om samfunnsspørsmål, politikk, kunst og historie, mot $14 \%(95 \% \mathrm{KI}$ : $11-16 \%$ ) av mennene. Sammenliknet med
1993 var det en signifikant dreining fra ikkemedisinsk faglitteratur mot skjønnlitteratur for begge kjønn. Lesemønsteret for ikkemedisinsk litteratur er vist i tabell 1.

Vi fant en svakt positiv, men statistisk signifikant sammenheng mellom tid benyttet til å lese ikke-medisinsk litteratur og tid til å lese faglitteratur $(\rho=0,07, p=0,05, n=875)$.

\section{Kulturbruk}

Svarerne rapporterte høy kulturell aktivitet. $81 \%$ (95\% KI: 79-84\%) hadde vært på kino i løpet av de siste 12 måneder, $78 \%$ (95\% KI: 76-81\%) på teater og $47 \%$ (95\% KI: $44-50 \%)$ i operaen. Tilsvarende tall for akademikere i befolkningen for øvrig var $90 \%$ (95\% KI: 86-94\%), $67 \%$ (95\% KI: $61-73 \%$ ) og $17 \%$ (95\% KI: $12-22 \%$ ) (13). Sammenliknet med andre akademikere går altså legene mindre på kino, men mer i teater og i operaen, bedømt etter $95 \%$ konfidensintervall.

Gjennomsnittlig kulturindeks var for kvinner 4,8 (95\% KI: 4,6-5,0) og for menn 4,6 (95\% KI: 4,4-4,7). Tilsvarende tall i 1993 var for kvinner 4,5 (95\% KI: 4,2-4,7) og for menn 4,1 (95\% KI: 3,9-4,2) (9). For både kvinnelige og mannlige leger har altså kulturindeksen økt fra 1993 til 2010, og for mennene er denne økningen statistisk signifikant. Vi fant signifikante positive korrelasjoner mellom kulturindeksen og jobbtilfredshet $(\rho=0,105, p=0,002, n=884)$, generell tilfredshet $(\rho=0,071, p=0,033, n=903)$, selvvurdert helse $(\rho=0,084, p=0,013$, $\mathrm{n}=881)$ og trening og annen fysisk aktivitet $(\rho=0,171, p<0,001, n=904)$. Dessuten korrelerte kulturindeksen negativt med jobbstress $(\rho=-0,102, p=0,003, n=866)$.

\section{Musikalsk aktivitet}

$58 \%$ (95\% KI: $55-61 \%)$ av svarerne anga at de kunne spille et instrument og $21 \%$ (95\% KI: $19-24 \%$ ) at de spilte regelmessig. $13 \%(95 \% \mathrm{KI}: 11-15 \%)$ anga at de for tiden var med i kor eller orkester. Tilsvarende tall for akademikere i befolkningen var henholdsvis $44 \%$ (95\% KI: 38-50\%), $11 \%$ (95\% KI: $7-15 \%$ ) og $9 \%$ (95\% KI: $5-13 \%)$ (13). Det synes altså å være flere leger som kan spille og som spiller regelmessig, mens forskjellen i aktiv deltakelse i kor eller orkester ikke er signifikant, bedømt etter $95 \%$ konfidensintervall.

Legene anga høyere musikalsk aktivitet $\mathrm{i}$ 2010 enn i 1993 (tab 2). Blant aktive musikanter var det desidert vanligste instrumentet piano/elektronisk orgel, fulgt av gitar/ strengeinstrumenter.

\section{Diskusjon}

Norske legers kulturelle og musikalske aktivitet er høy og har økt fra 1993 til 2010. I særdeleshet er interessen for og egenaktiviteten 
Tabell 2 Fordeling av leger som var aktivt med i orkester, kor, sang- eller musikkgruppe i 2010 sammenliknet med 1993 landel i prosent med $95 \%$ konfidensintervall). Med unntak av allmennmedisin og kirurgiske fag er endringene signifikante

\begin{tabular}{|c|c|c|c|c|}
\hline \multirow[b]{2}{*}{ Alle } & \multicolumn{2}{|c|}{$\begin{array}{c}1993 \\
(N=1031)\end{array}$} & \multicolumn{2}{|c|}{$\begin{array}{c}2010 \\
(N=1019)\end{array}$} \\
\hline & 8 & $(6-10)$ & 13 & $(11-15)$ \\
\hline \multicolumn{5}{|l|}{ Kjønn } \\
\hline Kvinner & 6 & $(5-8)$ & 12 & $(10-14)$ \\
\hline Menn & 9 & $(7-11)$ & 14 & $(12-16)$ \\
\hline \multicolumn{5}{|l|}{ Spesialitet } \\
\hline $\begin{array}{l}\text { Allmenn- } \\
\text { medisin }\end{array}$ & 12 & $(10-14)$ & 13 & $(11-15)$ \\
\hline $\begin{array}{l}\text { Laboratorie- } \\
\text { medisin }\end{array}$ & 3 & $(2-4)$ & 12 & $(10-14)$ \\
\hline $\begin{array}{l}\text { Indremedi- } \\
\text { sinske fag }\end{array}$ & 9 & $(7-11)$ & 13 & $(11-15)$ \\
\hline $\begin{array}{l}\text { Kirurgiske } \\
\text { fag }\end{array}$ & 7 & $(5-9)$ & 9 & $(7-11)$ \\
\hline Psykiatri & 9 & $(7-11)$ & 18 & $(16-20)$ \\
\hline $\begin{array}{l}\text { Samfunns- } \\
\text { medisin }\end{array}$ & 11 & $(9-13)$ & 15 & $(13-17)$ \\
\hline
\end{tabular}

innen musikk høy og høyere enn i en sammenliknbar gruppe av befolkningen for øvrig.

Egenrapportert aktivitet, som inkluderer hendelser 12 måneder tilbake i tid, vil være beheftet med feilkilder. Kanskje ønsker noen av svarerne å fremstå som mer kulturelt aktive enn det er grunnlag for i virkeligheten? Denne feilkilden er formodentlig den samme som ved vår sammenliknbare undersøkelse i 1993 (9) og i Statistisk sentralbyrås kartlegging av aktiviteten i den generelle norske befolkning $(12,13)$. Utvalget av leger er representativt for legegruppen i Norge, og med en svarprosent på 70 er det grunn til å tro at også svarerne er representative for gruppen.

Lesevanene hos folk flest er i endring. Andelen som leser en papiravis en gjennomsnittsdag, har sunket fra $85 \%$ i 1994 til $65 \%$ i 2009 i den norske befolkning i aldersgruppen 9-79 år (16). Forskjellen i avislesing mellom ulike utdanningsgrupper har samtidig økt. Mens det i 1994 var $83 \%$ med ungdomsskole og $92 \%$ med universitetsutdanning som leste avis daglig, var dette sunket til henholdsvis $62 \%$ og $84 \%$ i 2008 (12). Flere leger enn andre akademikere leser aviser, og reduksjonen i avislesing blant leger har vært mindre (fra 95\% til 90,5\%).

Til gjengjeld har boklesingen økt, både hos legene (fra $43 \%$ til $50 \%$ ) og hos andre akademikere (fra $33 \%$ til $43 \%$ ). Som i 1993 fant vi en positiv korrelasjon mellom lesing av medisinsk litteratur og lesing av ikkemedisinsk litteratur. De som leser mye, leser mye av begge litteraturkategorier.

Befolkningsundersøkelser viser at utdanning betyr mye for bruken av ulike kulturtilbud og betydelig mer enn husholdningsinntekten (16). Slik sett er det ikke overraskende at legenes kulturbruk er høy. Både antall teaterbesøk og spesielt antall operaforestillinger er høyere enn for andre akademikere.

Den største forskjellen mellom legene og befolkningen for øvrig fant vi i musikalsk aktivitet. Dobbelt så mange leger som andre akademikere spiller et instrument regelmessig. Det er påfallende at flere kvinnelige enn mannlige leger svarte at de kan spille et instrument, mens flere menn enn kvinner svarte at de spilte regelmessig. Andelen leger som svarte at de er med i kor eller orkester hadde økt fra $8 \%$ i 1993 til $13 \%$ i 2010 (9). Blant akademikere for øvrig har andelen ligges fast på $9 \%$ (16).

Mens vi i 1993 ikke fant noen sikker sammenheng mellom vår kulturindeks og legenes jobbtilfredshet, var det denne gangen en statistisk signifikant sammenheng: jo mer kulturell aktivitet utenfor jobben, desto høyere jobbtilfredshet, generell tilfredshet og bedre selvvurdert helse og desto mindre stress på jobben. Vi kan ikke utlede noen kausal sammenheng ut fra en tverrsnittsstudie, men våre funn sammenfaller med andre undersøkelser blant helsepersonell. I en tverrsnittsstudie blant knapt 3000 britiske leger var det en signifikant korrelasjon mellom legenes kulturelle og musikalske aktiviteter på fritiden og deres yrkesmessig engasjement (17).

Råd om sunne og helsebringende tiltak bør bygge på god dokumentasjon, fortrinnsvis basert på kontrollerte studier. Foreløpig er slik kunnskap om effekten av kulturell og musikalsk aktivitet sparsom. Men én randomisert, kontrollert studie er i hvert fall gjennomført. I Umeå ble 101 ansatte i helsesektoren randomisert til to grupper. Den ene gruppen ble eksponert for kino, konserter, kunstutstillinger eller deltok i sangkor i åtte uker. Intervensjonsgruppen skåret da høyere på selvrapportert helse, sosial funksjon og vitalitet (18). Det er for øvrig vanskelig å tenke seg store bivirkninger eller negative konsekvenser av slik aktivitet.

Det er god grunn for å slutte seg til sir Williams oppfordring: Kulturelle fritidsaktiviteter anbefales!

\section{Magne Nylenna (f. 1952)}

er direktør ved Nasjonalt kunnskapssenter for helsetjenesten.

Forfatter har fylt ut ICMJE-skjemaet og oppgir ingen interessekonflikter.

\section{Olaf Gjerløw Aasland (f. 1944)}

er forskningsleder ved LEFO - Legeforskningsinstituttet og professor ved Institutt for helse og samfunn, Universitetet i Oslo.

Forfatter har fylt ut ICMJE-skjemaet og oppgir ingen interessekonflikter.

\section{Litteratur}

1. Bryan CS. Osler: inspirations from a great physician. Oxford: Oxford University Press, 1997: 204.

2. Nylenna M. Livet er mer. Tidsskr Nor Lægeforen 1997; 117: 4357

3. Knudtsen MS, Holmen J, Håpnes 0 . Hva vet vi om kulturdeltakelse og helse? Tidsskr Nor Lægeforen 2005; 125: 3418-20.

4. Bygren LO, Konlaan BB, Johansson S-E. Attendance at cultural events, reading books or periodicals, and making music or singing in a choir as determinants for survival: Swedish interview survey of living conditions. BMJ 1996; 313: 1577-80

5. Konlaan BB, Bygren LO, Johansson SE. Visiting the cinema, concerts, museums or art exhibitions as determinant of survival: a Swedish fourteenyear cohort follow-up. Scand J Public Health 2000; 28: 174-8

6. Wilkinson AV, Waters AJ, Bygren LO et al. Are variations in rates of attending cultural activities associated with population health in the United States? BMC Public Health 2007; 7: 226.

7. Cuypers K, Krokstad S, Holmen TL et al. Patterns of receptive and creative cultural activities and their association with perceived health, anxiety, depression and satisfaction with life among adults: the HUNT study, Norway. J Epidemiol Community Health 2012; 66: 698-703.

8. Aasland OG, Kallevik SA. Er leger mer interessert i musikk enn andre yrkesgrupper? Tidsskr Nor Lægeforen 1993: 113: 3737-42.

9. Nylenna M, Aasland OG, Falkum E. Survey of Nor wegian doctors' cultural activities. Lancet 1996; 348: $1692-4$.

10. Aasland OG, Rosta J. Hvordan har overlegene det? Overlegen 2011; 1: 47-55.

11. Aasland OG, Rosta J. Fastlegenes arbeidstid. Tidsskr Nor Legeforen 2011; 131: 1076-9.

12. Vaage OF. Norsk kulturbarometer 2008. Oslo/ Kongsvinger: Statistisk sentralbyrå, 2009.

13. Vaage OF. Norsk mediebarometer 2009. Oslo/ Kongsvinger: Statistisk sentralbyrå, 2010

14. Warr P, Cook J, Wall T. Scales for the measurement of some work attitudes and aspects of psychological well-being. J Occup Psychol 1979; 52 : 129-48.

15. Siegrist J. Adverse health effects of high-effort/ low-reward conditions. J Occup Health Psychol 1996: 1: 27-41

16. Vaage OF. Kultur- og mediebruk i forandring. Bruk av kulturtilbud og massemedier fra 1991 til 2006. Statistiske analyser nr. 95. Oslo/Kongsvinger: Statistisk sentralbyrå, 2007.

17. McManus IC, Jonvik H, Richards P et al. Vocation and avocation: leisure activities correlate with professional engagement, but not burnout, in a crosssectional survey of UK doctors. BMC Med 2011; 9 . 100

18. Bygren LO, Weissglas G, Wikström BM et al. Cultural participation and health: a randomized controlled trial among medical care staff. Psychosom Med 2009; 71: 469-73.

Mottatt 3.1. 2013, første revisjon innsendt 22.2. 2013, godkjent 8.4. 2013. Medisinsk redaktør Are Brean. 